\title{
Evaluation of an In-Service Training Program for Primary School Teachers of English in Vietnam
}

\author{
Bui Phu Hung ${ }^{1}$ \\ ${ }^{1}$ Faculty of Foreign Languages and Cultures, Van Hien University, Ho Chi Minh City, Vietnam (Currently as a \\ doctoral candidate of TESOL at Hue College of Foreign Languages, Vietnam) \\ Correspondence: Bui Phu Hung, Faculty of Foreign Languages and Cultures, Van Hien University, Ho Chi Minh \\ City, Vietnam. E-mail: buiphuhung@yahoo.com
}

Received: May 15, $2016 \quad$ Accepted: June 10, $2016 \quad$ Online Published: July 13, 2016
doi:10.5539/ijel.v6n4p96
URL: http://dx.doi.org/10.5539/ijel.v6n4p96

\begin{abstract}
Project 2020 aims at developing in-service primary school EFL teachers' profession in Vietnam. This current study investigates in-service teachers' and administrators' opinions of different aspects of the project by analyzing their responses to the questionnaire and interviews. Findings show that they are generally in a moderate agreement with aspects of the in-service training program; however, they are concerned about management, training model, and materials and resources. They also want to be given more time to practice and exchange opinions. Their satisfaction with the course greatly depends on the course content. Recommendations are made for future retraining courses.
\end{abstract}

Keywords: teacher education, participants' satisfaction, INSET program evaluation

\section{Introduction}

\subsection{Background of the Study}

In order to improve Vietnamese students' English proficiency, Vietnam has carried out several projects, one of which is the National Foreign Languages Project 2008-2020 introduced by the Ministry of Education and Training (MOET). It is estimated that 12,000 well-qualified teachers will be needed for all Vietnamese primary schools (Hayes, 2008). In-service training (INSET) is worth a concern and MOET has implemented INSETs for EFL primary school teachers throughout Vietnam. Its goals are supposed to basically improve their language competencies to achieve First Certificate in English (FCE) in Common European Framework Reference as well as methodology (MOET, 2011).

Departments of Education and Training of all cities and provinces in the country have been involved. Each of them is in charge of the planning and implementation of the INSET for the local schools financed by the government. Besides, worshops of similar issues have been carried out by institutions in the hope for supplementing neccessary knowledge and skills for the local teachers.

This current research study is believed to reflect opinions of the INSET participants and their managers about the INSET program so that appropriate renovations will be made in the second stage in order to achieve the objectives of the whole program.

\subsection{The Significance of the Study and Research Questions}

A question arises if local agencies have enough qualified trainers for the intended training. Some rural contexts may not really have sufficient competencies to fulfil the goals (Nguyen, 2012). Another concern may be about how the in-service training has been implemented.

This current study is to discover the strengths and weaknesses of the aforementioned INSET program in Ho Chi Minh City in Vietnam in the hope to evaluate the courses taken and make implications for developing later training courses. The research questions are:

1) To what extent did the participants appreciate the in-service training courses they attended?

2) What areas of the program should be further improved?

3) What factor was the most significant to the overall evaluation of the INSETs? 


\section{Literature Review}

\subsection{Related Studies}

Huong \& Yeo (2016) did a case study on evaluating retraining of elementary teachers of English in Central Vietnam. Sixty teachers answered questionnaires with sixteen statements in a Likert scale and fifteen others were interviewed randomly. The evaluation focused on the content, materials, methods, and management. The findings revealed that respondents, in general, highly appreciated the in-service training they had experienced. They were also concerned about several issues. Firstly, the content needed to be more practical. Secondly, the participants wanted to be given more time for practicum and discussion. Finally, teachers in service should have had equal opportunities to receive training.

Uysal (2012) did a study on evaluating a retraining course for primary language teachers in Turkey. The researcher interviewed three teacher trainers and six participants teachers. 72 teacher participants were given a questionnaire. The questionnaire focused on the course participants'level of satisfaction with the in-service training course, perceived influence of the course on trainees'self-perception, motivation, knowledge-base and classroom practices. The researcher concluded that a top-down one-shot manner could not guarantee the achievement of educational reform. In order for an in-service training course to be successful, there should have been cooperation between authorities, trainers and trainees throughout the retraining course. Also, the management should also pay attention to method input, resources and materials. Participants' feeback needs to be collected and their participation should be valued and monitored.

Nguyen (2012) did a research study on the implementation of CEFR in Vietnamese rural contexts. Sixty-four principals and forty seven teachers of English are involved in the study. According to the findings, most objectives of the policy were not fully achieved. A recommendation was the government should have placed more emphasis on in-service training so that teachers could be more qualified to fulfill the intended requirements in terms of teaching methods, content and materials. One of the approaches would be ongoing professional development for teachers through the Internet for those who could not attend the training in person.

\subsection{Components of Program Evaluation}

Any evaluation of a training program should look at its objectives as they are the ones educators first determine in order to develop the curriculum. The other components, such as content, methods, materials, should be the follow-up steps. In other words, the content, methods, materials and other parts of a training program should be based on the set objectives. An explanation is educators and managers may find it hard to know what should be taught, how the lessons should be delivered, how qualified the teachers should be and how much the financial resource is needed for the training if the objectives are not figured out in advance of the implementation (Sallis, 1993). Another explanation is that the goals will help determine the expected outcome or output so that testing methods and certification will be done within a planned path at the end of the course (Lynch, 1996; Murphy, 1985). Murphy (1985) also discusses the relationships between objectives with other parts of a training program in which objectives are not always fixed, but any change to objectives should be based on evaluation, content and methods.

Content is one of the most significant parts of a program which evaluators can look at to know if learners' needs are met. In other words, curriculum designers should identify and analyze learners' needs to construct the curriculum as trainees, especially in-service ones, may refuse to engage in learning if they find the content does not satisfy their expectations.

In the context where stakeholders in the private sector send their employees for retraining, course attendants' and managers' expectations may be analyzed in prior to the curriculum development. However, in the public sector, course objectives may be set by governmental agencies in which in-service trainees work; therefore, the analysis of needs can be somewhere between the setting of the objectives and the curriculum designing (White, 1988). The following diagram can illustrate the process (Figure 1).

Another indispensable part of a curriculum is how lessons should be delivered. This depends primarily on available human resources and the course objectives which can be set by managers in project-based approach, from trainees' needs or both.

In the places where there is a shortage of skilled or well-qualified trainers, outsourcing can be a feasible measure. The limited funding, nevertheless, may let the stakeholders think of taking advantage of available local resources (Bramley, 1986).

Materials can be in print or online since learning is not restricted to the classroom. Intensive and extensive learning methods can be combined. Lessons and lectures can be available on a particular website introduced to 
course participants. The flexi-time learning mode and further references give the trainees more opportunities to access knowledge.

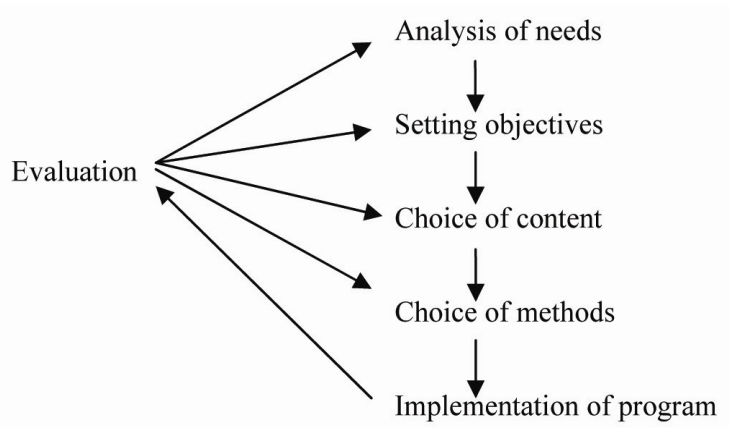

Figure 1. The relationships between evaluation and program elements (adapted from Bramley, 1986)

The materials in print should state good guidance on learning. Textbooks, in particular, must clearly state how an item should be learned and include supplementary practices. Also, the textbook also needs to reflect the goals and there should be teacher's manual with suggested answers (Huong \& Yeo, 2016).

\subsection{Important issues in INSET Programs}

The management can be task-oriented, people-oriented or both. In case of retraining, the training time should be staggered with the participants' working schedule. For example, the in-service training can be organized elsewhere during the summer break. In addition, feedback should be collected as reflection to improve follow-up or successive courses. Modules should be arranged appropriately from the easiest to the hardest or be theme-based. Assessments and certification are also worth the managers' concern. The course organizers must think of how to assess the attendants and what should be involved. Certificates should be awarded at the end of the course as evidence of their attendance.

How qualified the trainers should be is another concern which plays a crucial role in how successful the course will be and what the outcome will be like. In the area of in-service training for primary school teachers of English, trainers can be university professors who have conducted research on teaching English to children or variables of young learners (Wallace, 2001, p. 9). In addition, trainers can be experienced primary school teachers of English whose students have been awarded honor certificates of English proficiency or who have been considered good teachers (Wallace, 2001, p. 15).

In-service training may be financed by an organization or the government. In this case, all the potential costs should be regarded in advance. However, in the context where trainees have to pay the total or partial fee, it must be affordable so that all trainees or INSET teachers can attend and update the expected knowledge and skills (Burgess, Connor, Galloway, Morrison, \& Newton, 2013, p. 113).

Kirkpatrick (1998) believes evaluation of an INSET program should involve the participants' employers' or managers' opinions of their performance as a result of the retraining. In other words, what the teachers have learned from the training needs to meet their head teachers or immediate managers' expectations.

Guskey (2000) believes the evaluation of INSET programs for teachers should focus on participants' satisfaction with the courses they have attended, aim at the effectiveness of the program and collect feedback from the managers who directly supervise the participants in their work places.

\section{Research Methodology}

\subsection{Participants}

There were three groups of participants. The first group comprised 100 teacher participants who were given the questionnaire (Appendix 1) with 25 questions focusing on eight main different areas of the INSET attended, namely content (Questions 1-5), methods (Questions 6-8), materials (Questions 9-11), management (Questions 12-15), teachers (Questions 16-19), objectives (Question 20), acceptability (Questions 21-23), attendance fee and funding (Question 24). Also, there is an overall evaluation of the INSETs (Question 25). The second group consisted of thirty course participants who were asked open-ended questions for their opinions of the aforementioned aspects of the INSET. The teachers in these two groups came from sixteen different primary schools in Ho Chi Minh City. The third group, who was also interviewed, consisted of seventeen head teachers 
of the schools where the retrained teachers worked. These head teachers, who were asked open-ended questions, were the immediate supervisors of the surveyed participants and were also the communicators between the participants and program administrators of the INSETs. Questions 1-7 asked for their comments on the objectives, curriculum, implementation, funding, teachers' improvements, acceptability of the output, and feedback collection. Questions 8 and 9 asked about their further comments and recommendations for future INSETs.

\subsection{Research Methods}

A pilot study was implemented with 10 participants whose responses were not used for the main study to make appropriate amendments to the questionnaire, but no changes was made because these respondents' answers were absolutely relevant and they did not make any further recommendations. The questionnaire was prepared on the Likert type scale from 1 to 5 ( 1 for strong disagreement and 5 for strong agreement). According to Gabrscek \& Roeders (2013), questionnaire and interviews are the main source of information about aspects of the INSET program.

This current study was both qualitative and quantitative. The results from the questionnaire were analyzed via SPSS. Descriptive statistics, including frequencies, mean scores and standard deviation. Correlations between variables and coefficients of variables were also examined through variance (ANOVA) and independent t-test.

\section{Data Analysis and Discussion}

In general, the majority of the mean scores were around 3.5; that is, the participants had positive attitudes towards the statements (Table 1). The criteria of evaluation will be made one by another, combining data collected from the questionnaire and interviews.

Table 1. Participants' opinions of aspects of the INSETs

\begin{tabular}{|c|c|c|}
\hline Items $(\mathrm{N}=100$, Missing $=0)$ & Mean & SD \\
\hline 1. The content of the INSETs was relevant and updated. & 3.53 & 0.915 \\
\hline 2. The content of the INSETs was helpful for my job. & 3.65 & 0.903 \\
\hline 3. The content was practical and applicable. & 3.63 & 1.002 \\
\hline 4. The content of the INSETs covered aspects of teaching English to young learners. & 3.73 & 0.863 \\
\hline 5. There was appropriate theory-practice balance. & 3.48 & 0.847 \\
\hline 6. The teaching methods were interesting. & 3.48 & 0.904 \\
\hline 7. The trainees were given time for raising questions. & 3.43 & 0.879 \\
\hline 8. The trainees were given time for sharing knowledge and experience with other participants. & 3.49 & 0.882 \\
\hline 9. The materials were sufficient and practical. & 3.44 & 1.008 \\
\hline 10. There was sufficient guidance for self-study. & 3.19 & .895 \\
\hline 11. Further references were introduced. & 3.42 & 0.878 \\
\hline 12. The INSET program did not interfere with my teaching as I was allowed to attend the courses. & 3.58 & 0.867 \\
\hline $\begin{array}{l}\text { 13. There was overall assessment of participants' competencies and certificates were awarded for attending } \\
\text { the courses. }\end{array}$ & 3.33 & 1.045 \\
\hline 14. Feedback from the participants was collected. & 3.60 & 1.015 \\
\hline 15. The INSETs were organized logically (theme-based or in order of difficulty). & 3.50 & 0.905 \\
\hline 16. The trainer clearly presented the objectives of each lesson. & 3.69 & 0.873 \\
\hline 17. The trainer's instruction was understandable and clear. & 3.69 & 0.837 \\
\hline 18. The trainer's answers were persuasive. & 3.68 & 0.920 \\
\hline 19. The trainer inspired the learners. & 3.53 & 0.948 \\
\hline 20. The objectives of the program were realistic and sufficiently provided to participants. & 3.54 & 0.881 \\
\hline 21. I have applied what I learned from the INSETs. & 3.38 & 0.763 \\
\hline $\begin{array}{l}\text { 22. My school has encouraged me to apply what I learned from the retraining to the classes which I have } \\
\text { taught. }\end{array}$ & 3.78 & 0.799 \\
\hline $\begin{array}{l}\text { 23. The students have developed (results, students' attitudes, atmosphere...) when I apply what I learned } \\
\text { from the INSETs. }\end{array}$ & 3.51 & 0.847 \\
\hline 24. The fee was suitable. & 3.58 & 1.121 \\
\hline 25. Overall, I highly appreciate the INSETs I attended. & 3.58 & 0.997 \\
\hline
\end{tabular}

Table 2 illustrates the ranking of different aspects of the whole program. The mean scores and standard deviations show that they agreed with all aspects of the whole program and the statistics were reliable. They expressed that management, methods and materials were least agreeable. However, they highly appreciated 
teachers and content.

\subsection{Trainers}

The participants generally had positive feedback on teachers, with the mean score of 3.65 (Tables 1 and 2). The responses to the statements $16,17,18$ and 19 show the participants' moderate agreement with the teachers' performances. What the participants were concerned about the teachers was they did not really motivate the participants to learn.

Eight interviewees made comments on the teachers' performances, half of which were positive in that they appreciated learning with foreign teachers in improving their English competencies. However, the other half responded that the teachers' answers were unconvincing or they delayed answering the questions raised in the classroom.

\subsection{Funding and Fees}

The mean score for the fee was 3.58; that is, the participants moderately agreed with the paid fee. Nevertheless, the standard deviation was over 1. This was explainable as the opinion of how much the fee should have been depended on each participant's own financial status.

Table 2. Participants' satisfaction with aspects of the INSET program

\begin{tabular}{llll}
\hline Criteria (N=100) & Mean & SD & Rank \\
\hline Trainers & 3.65 & .768 & 1 \\
Content & 3.64 & .781 & 2 \\
Fee & 3.58 & 1.121 & 3 \\
Overall assessment & 3.58 & .997 & 3 \\
Acceptability & 3.56 & .661 & 4 \\
Objectives & 3.54 & .881 & 5 \\
Management & 3.50 & .711 & 6 \\
Methods & 3.46 & .707 & 7 \\
Materials & 3.39 & .728 & 8 \\
\hline
\end{tabular}

The managers, when asked about the funding, responded that the program was partially financed by Department of Education and Training. The participants themselves or their affiliations had to pay some fee. Some institutions did not provide sufficient financial support for their teachers' INSETs and had to have their teachers cover part of the fee. That was why one trainee teacher, during the interview, revealed that the fee was unaffordable to him.

\subsection{Content}

Correlations between items of content were significant at 0.01 level. It was rated the second, after teachers' competencies (Table 2). However, it was what most participants made comments on. Nine interviewees said that the class size of the model they observed and practiced in the INSET was much smaller than the real one. Also, four others believed the content was not really updated. Two others thought they should have been trained in the use of interactive white board. Three others argued that the lessons were more theoretical than practical. Finally, ten interviewees said the training of English competencies was not effective in that the lessons were not test-oriented, which led to many participants' failure in FCE.

Ten managers, in the interview, believed the content was theme-based and logical; however, the content of the whole curriculum should have been sent to the participants' workplaces prior to the start of the course so that the participants could have had appropriate preparations for the training. Two others would like to have their teachers trained in the use of games in English language teaching.

\subsection{Management, Methods and Materials}

The training methods and management were what participants rated around the bottom of the list (Table 2). Their biggest concern about the methods was that they were not given sufficient time for asking questions. Correlations between the items of methods and of materials were significant at 0.01 each (2tailed). Correlations between items of management were significant at 0.01 or 0.05 level (2tailed).

Eleven course participants argued that the INSET courses should have been organized in the summer when they were available for training. They added the training should not have been tightly scheduled as they could not consume all the input at one shot. Four others believed the management of the project should have sent materials 
to participants, maybe via the affiliations where they worked, so that they could have been better prepared for the INSET. Two others made a suggestion that the number of participants in each course should have been reduced. Both managers and participants believed program administrators collected opinions from both participants and their managers, but this was done at only some schools, which did not generalize the real needs. Finally, seven interviewees would like to receive assessment of their competencies and certificates for their attendance.

Nine managers interviewed said that most courses were scheduled in the weekend and did not really interfere with their teachers' work. However, the training which took place in the summer would have been suitable for all the INSET participants.

Seven interviewees would like to receive more materials for reference. They believed handouts from teachers and materials provided were limited. Further references were crucial to improving their knowledge base.

\subsection{Objectives}

The mean score for the objectives of the program was 3.54 (Table 2); that means, participants, in general, agreed that the objectives were realistic and sufficiently provided to them.

When asked, seventeen managers responded that the objectives were based on analysis of needs and clearly informed. However, seven of them added teachers of different schools might have different backgrounds; therefore, the generalization in the training objectives could have caused difficulties to teachers in suburban areas.

\subsection{Acceptability}

Correlations between items of acceptability were significant at 0.01 level (2tailed). The mean score was 3.56 (Table 2) indicating what the trainees had learned from the INSETs was generally appreciated at their workplaces. ANOVA shows that this acceptability was in positive correlations with how they were trained, what they were trained in and how competent the trainers were (Table 3).

The trainees believed that their classroom improved to a certain extent (table 1) when they applied what they learned from the course. All the respondents said that they were encouraged by their managers (head teachers) to do it during the interview.

All the managers interviewed agreed that their teachers improved in terms of both language competencies and methodology. One of them added 'But some teachers did not improve much and others were not eager to apply the new methods learned".

\subsection{Overall Evaluation}

ANOVA was used to figure out there were strong correlations between the perceived overall evaluation and content, teachers, training methods and acceptability, in which content was the key factor of the overall evaluation of the INSET (Table 3). The correlations between evaluation criteria were significant at 0.01 level (2tailed).

Table 3. Correlations between criteria of evaluation

\begin{tabular}{llllllllll}
\hline $\mathbf{N}=\mathbf{1 0 0}$ & Overall evaluation & objectives & Fee & Content & Methods & Materials & Management & Trainers & Acceptability \\
\hline Overall evaluative & 1 & $.537^{* *}$ & $.473^{* *}$ & $\mathbf{. 7 0 9}^{* *}$ & $.689^{* *}$ & $.562^{* *}$ & $.561^{* *}$ & $.698^{* *}$ & $.685^{* *}$ \\
\hline
\end{tabular}

**. Correlation is significant at the 0.01 level (2-tailed).

All the seventeen interviewed managers made a positive evaluation of the whole training program. They also would like to send their teachers to courses of the same type.

\subsection{Further Comments}

Three managers responded in the interview that they would like to have their teachers trained in English language teaching in countries using English as a second or native language in order that their teachers could have improved in terms of both language competencies and methodology. Another manager from a state school was concerned about the selection of teachers done by the Department of Education and Training. He argued that the objectives of the INSETs could have been realistic if there had been criteria for recruiting teachers. The state schools were not involved in the recruitment at all.

In comparison with the previous studies conducted in the country and in the world, this current study included the teachers' immediate managers' opinions of their professional development as a result of the retraining. The 
teachers' classrooms are thought to improve by both the teachers themselves and their head teachers. Secondly, the findings also prove that the content was the key aspect of INSET participants' satisfaction with the course. These contributions set the ground for later studies in the field and implementation of following programs.

\section{Conclusion}

\subsection{General Discussion}

In general, the INSETs met participants' and their managers' expectations. They provided positive comments on aspects of the INSETs. However, the top-down approach of Project 2020 in Vietnam was considered to encounter challenges right at its start as its objectives were intense. This current study was successful in collecting and reflecting participants' and their managers' opinions of the project.

Management of the project was deemed to be really problematic in that lacks of references for trainees, necessary planning and analysis of needs were the main concerns to the participants. The most serious problem rested against lack of communications between the project management, INSET teachers and primary school managers.

The mean score of the acceptability was 3.56, which shows that the trainees' application of what they had learned from the INSET was encouraged and accepted at their schools. Data from the interviews also supported this result.

The most significant factor that influenced participants' overall evaluation of the program was content. This was in line with international studies in learners' satisfaction with their courses (Lee \& Lee, 2014; Jorge, 2012).

\subsection{Limitations of the Study}

The evaluation of the program in this current study was based on participants' and their immediate managers' feedback through the questionnaire and interviews. The lack of observation did not give the researcher information about what the trainers and trainees did during the INSETs. Secondly, information about if the applicability of the training result was only collected through the trainees' and school managers' opinions. Pre-test and post-test were not used to measure the effectiveness of the aforementioned INSETs.

\subsection{Recommendations}

In the following training courses, the involvement and commitment of more stakeholders should be encouraged so that participants will have more opportunities to attend the program and to make demonstrations and practice. Materials and resources, planning and trainers, as a result, may be improved.

Secondly, the primary school managers and teachers need to be informed about the whole curriculum as well as the training process so that they will have appropriate preparation to obtain the goals. The class model which they observe and practice should be similar to the one in the contemporary educational context, including learner variables and class size.

A participant-centered approach should be practiced. For instance, analysis of needs should be done to construct the curriculum prior to the introduction of the program, and feedback should be collected during the training to make adjustments of the content. Also, during the course, participants should be given more time for discussion and raising questions. Online forum and confessions are necessary so that they can exchange and share their knowledge and resources (Clarke, 1983, pp. 109-110; Wolter, 2000, p. 135).

Course specialization should be taken into consideration. Participants, during the interview, revealed that they would like to learn to particularly teach young learners, not general teaching methods and how to apply games to teaching English. Their concern may stem from the situation that the course content did not specialize in teaching English to young learners.

Finally, assessment and certificates should be given for their participation and contributions as evidence of their professional development in order to improve the quality of the training and participants' appreciation of the course.

\section{Acknowledgements}

The researcher would like to send thanks to Assoc. Prof. Dr. Le Pham Hoai Huong at College of Foreign Languages, Hue University for her inspiration for this research study. Great thanks would also go to Assoc. Prof. Dr. Truong Vien for his supervision and advice on the implementation of this current study. Final thanks would go to all the participants involved. 


\section{References}

Bramley, P. (1986). Evaluation of training: A practical guide. London: British Association for Commercial and Industrial Education.

Burgess, R. G., Connor, J., Galloway, S., Morrison, M., \& Newton, M. (2013). Implementing in-service education and training. New York: Routledge.

Clarke, M. A. (1983). The scope of approach, the importance of method, and nature of technique. In J. E. Alatis, H. E. Stern, \& P. Stevens (Eds.), Applied Linguistics and the Preparation of Second Language Teachers: Toward a Rationale (GURT 1983). Washington, DC: Georgetown University Press.

Gabrscek, S., \& Roeders, P. (2013). Analysis of the existing ETTA INSET system and assessment of the needs for in-service training of teachers. Education and Teacher Training Agency.

Guskey, T. (2000). Evaluating professional development. Thousand Oaks: CA. Corwin Press.

Hayes, D. (2008). Primary English language teaching in Vietnam. Evaluating in-service training of primary English teachers: A case study in Central Vietnam, Asian EFL, 18(1), 34-51.

Huong, L. P. H., \& Yeo, M. (2016). Evaluating in-service training of primary English teachers: A case study in Central Vietnam. Asian EFL, 18(1), 34-51.

Jorge, L. (2012). Critical factors that influencing in service teachers' satisfaction with an e-learning course measured with s structural equation modeling. Proceedings of EDULEARN12 Conference, 2449-2452.

Kirkpatrick, D. L. (1998). Evaluating training programs: An overview. San Francisco: Berret-Koewer Publications.

Lee, S. Y., \& Lee, H. S. (2014). Analysis of the influence of factors related to student satisfaction with web-based university courses: Comparison between 2005 and 2014. Advanced Science and Technology Letters, 59, 76-80. http://dx.doi.org/10.14257/astl.2014.59.17

Lynch, B. K. (1996). Language program evaluation. Cambridge: Cambridge University Press.

MOET. (2011). Notice on In-service training program for primary school teachers. Retrieved from www.moet.gov.vn/?page $=6.10 \&$ view $=3620$

Murphy, D. F. (1985). Evaluation in language teaching: assessment, accountability and awareness. In C. Alderson (Ed.), Lancaster practical papers in English language education. Frankfurt: Pergamon.

Nguyen, T. T. T. (2012). English language policies for Vietnamese primary schools and issues of implementation in rural settings. Asia TEFL, Special Issue, 115-134.

Sallis, E. (1993). Total quality management in the educational context. London: Kogan Page.

Uysal, H. H. (2012). Evaluation of an in-service training program for primary school language teachers in Turkey. Australian Journal of Teacher Education, 37(7). http://dx.doi.org/10.14221/ajte.2012v37n7.4

Wallace, M. J. (2001). Training foreign language teachers: A reflective approach. Cambridge: Cambridge University Press.

White, R. V. (1988). The ELT curriculum: design, innovation and management. London: Basil Blackwell.

Wolter, B. (2000). A participant-center approach to INSET course design. ELT Journal, 54(4), 311-318. http://dx.doi.org/10.1093/elt/54.4.311

\section{Copyrights}

Copyright for this article is retained by the author(s), with first publication rights granted to the journal.

This is an open-access article distributed under the terms and conditions of the Creative Commons Attribution license (http://creativecommons.org/licenses/by/3.0/). 